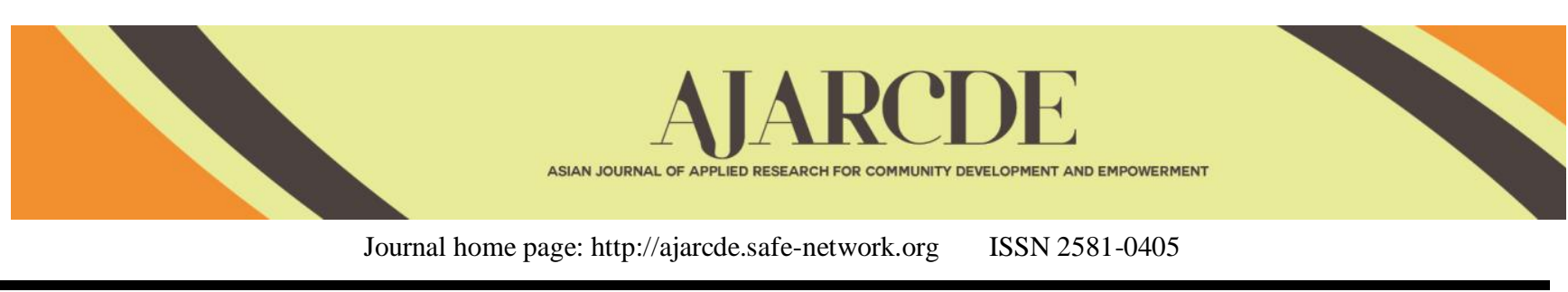

\title{
Household Biomass Gas Stove Performance and Exhaust Gas Emission
}

\author{
S N Jansri ${ }^{1 *}$, M Kumpanalaisatit ${ }^{1}$ and T Sataklang ${ }^{1}$ \\ 1 Asian Development College for Community Economy and Technology (adiCET), Chiang Mai Rajabhat University, Thailand 50180. \\ Corresponding author: jansrisnar@gmail.com
}

\section{ARTICLE INFO}

Article History:

Received: July 29, 2019

Final Revision: November 24, 2019

Available Online: December 21, 2019

\section{KEYWORDS}

Biomass gas stove, Updraft gasification,

Household stove, Performance, Exhaust gas.

\section{CORRESPONDING AUTHOR}

*E-mail: jansrisnar@gmail.com

\section{A B S T R A C T}

This work focuses on the design of the household biomass gas stove which is suitable for the lifestyle of the Thai northern people. In addition, the performance and exhaust emission of the stove - updraft gasifier - was design per the community requirement were evaluated. The stove consists of a combustion chamber - a primary chamber - and a secondary chamber with the primary and secondary air inlet of 0.016 and $0.002 \mathrm{~m}^{2}$, respectively. Moreover, the flow rate of primary air and secondary air was 0.456 and $1.340 \mathrm{~kg} / \mathrm{s}$, respectively. The performance of the stove was analyzed by the water boiling test technique and the emission of exhaust gas was evaluated with a fuel gas analyzer. The result indicated that the thermal efficiency of the stove was $44.84 \%$. The specific fuel consumption was $0.029 \mathrm{~kg} / \mathrm{kg}$ of water. Comparing the designed stove with the traditional clay brazier stove, the performance of the designed stove was higher than the traditional stove. The emission comparison between the designed household biomass gas stove, the traditional stove and the Thai exhaust gas emission standard indicated that both stoves released $\mathrm{NO}_{\mathrm{x}}$ and $\mathrm{SO}_{2}$ which are less than the standard whereas $\mathrm{CO}$ emission of the designed stove conformed to the standard. This work confirmed that the efficiency and the exhaust gas emission of the designed stove are better than the traditional stove. Therefore, this household biomass gas stove could replace the conventional stove.

\section{INTRODUCTION}

Although various alternative energies are presently offered for household cooking, most rural people in the Northern of Thailand still preferred to use biomass - firewood, twigs, agricultural residual and charcoal as traditional fuel for their kitchen. The clay brazier stoves are also used for preparing food in their home until now. The technology results in incomplete combustion and high levels of indoor pollution which is carbon monoxide and small particles [1]. Even though, the people know that the traditional stove would cause adverse effect on health, they do not change their behavior.

A biomass gas stove, a cleaner technology, approaches for generating heat from biomass in a completely way. The biomass gas stove promotes a chemical reaction between combustible gases $\left(\mathrm{CO}, \mathrm{H}_{2}, \mathrm{CH}_{4}\right.$ and hydrocarbons) and an atmospheric oxygen to produce heat. The combustible gases are carried out from a partial combustion of carbonaceous fuel in a limited primary air environment whereas the combustion occurs due to the oxidation reaction between producer gas and a separate flow of air (a secondary air) [2,3].

Top lit updraft biomass gas stoves meet cooking current behavior. Therefore, these stoves have developed for combusting between producer gas from solid biomass and the hot air. Supramono et al. [2] designed the top lit updraft biomass gas stove using rubber wood pellets as a fuel. the stove was equipped with 2 blowers for feeding air into the primary and secondary chamber, respectively. The highest efficiency of stove was $58.5 \%$. Similarly, Solapure et al. [4] designed biomass gas stove using sawdust as a fuel equipped with the blower. The result indicated that the stove given consistent blue flame and had the average thermal efficiency of $36.5 \%$. The biomass gas stoves as above mention were operated under forcing of air flow which were not suitable for remote area without electricity. The problem was solved by other researchers such as Igboanugo et al. [5] designed and constructed the biomass gas stove for cooking in Nigeria with natural air flow. A woody biomass was used as a fuel for the stove. The stove had a maximum thermal efficiency and the percentage heat utilization of 55\% and 54\%, respectively.

Although are many biomass gas stoves design for local purpose, they may be not suitable for the lifestyle of the Thai northern people. Therefore, this work focuses on the design of the household biomass gas stove for working on a natural air flow mode in line with their lifestyle. In addition, the performance and exhaust emission of the stove were evaluated.

\section{MATERIALS AND METHODS}

The top lit updraft gasifier having function being similar to the traditional stove (the clay brazier stove) of 30-cm height and 30$\mathrm{cm}$ diameter is a suitable technology per the community 
requirement. The stove consisting of two chambers: a combustion chamber equipped with a fuel inlet and a hot air chamber. The stove was design under the efficiency of $50 \%$.

A $0.005 \mathrm{~m} 3$ chamber was design as the combustion chamber - a primary chamber - to accommodate the loading of firewood $0.5 \mathrm{~kg} / \mathrm{batch}(2 \mathrm{~kg} / \mathrm{hr})$. This chamber was placed in the middle of a secondary air chamber (the hot air chamber) $(0.016 \mathrm{~m} 3)$ without insulation as shown in Figure 1. During combustion, the air flowed into the bottom of the stove and was separated for flowing into 2 chambers. The first part air with the flow rate of $0.456 \mathrm{~kg} / \mathrm{s}$ flowed into the primary chamber having the air inlet of $0.016 \mathrm{~m} 2$ for promoting the pyrolysis process (the partial combustion process). The other one flowed into the secondary chamber having the air inlet of $0.002 \mathrm{~m} 2$ with the flow rate of $1.340 \mathrm{~kg} / \mathrm{s}$. The secondary air was warmed with the heat generating by the partial combustion of the primary chamber before flowing into the combustion process at the top of stove.

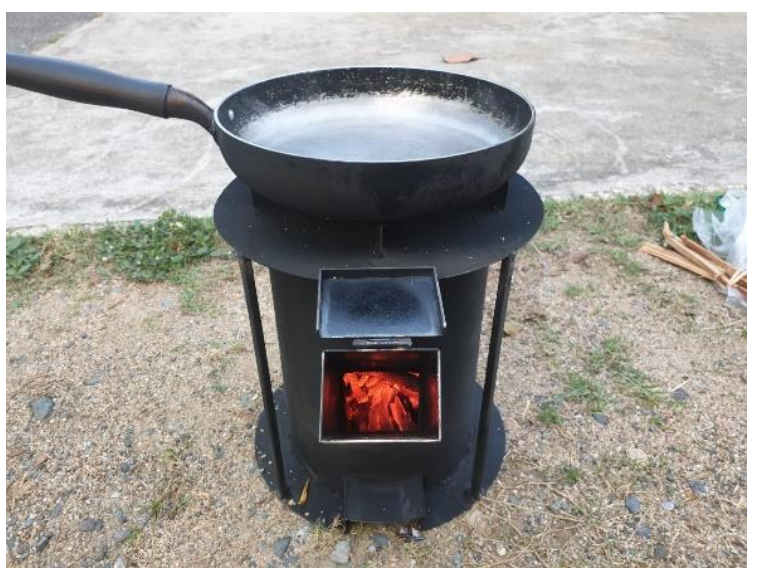

Figure 1. Household biomass gas stove

The performance of the stove was analyzed by the water boiling test technique [5]. The emission of exhaust gas was evaluated with fuel gas analyzer comparing with the clay brazier stove and the Thai exhaust gas emission standard [6].

\section{RESULT AND DISCUSSION}

\subsection{The performance of biomass gas stove}

The result indicated that the thermal efficiency of stove was $44.84 \%$. The specific fuel consumption was $0.029 \mathrm{~kg} / \mathrm{kg}$ water. Comparing the designed stove with the traditional clay brazier stove, the performance of the designed stove was higher than the traditional stove.

\subsection{The emission of biomass gas stove}

This stove released $\mathrm{O}_{2}, \mathrm{CO}, \mathrm{CO}_{2}, \mathrm{NO}_{x}, \mathrm{SO}_{2}$ and $\mathrm{H}_{2}$ at $12.59 \%$, $385 \mathrm{ppm}, 7.37 \mathrm{ppm}, 99 \mathrm{ppm}, 0 \mathrm{ppm}$ and $8 \mathrm{ppm}$, respectively as shown in Table 1 . However, the exhaust gas emission of designed stove was less than the traditional stove, except for, NOx and SO2 being equal. The emission comparison between the designed household biomass gas stove, the traditional stove and the Thai exhaust gas emission standard indicated that both stoves released $\mathrm{NO}_{\mathrm{x}}$ and $\mathrm{SO}_{2}$ which are less than the standard whereas $\mathrm{CO}$ emission of the designed stove conformed to the standard.
Table 1. The emission of biomass gas stove, traditional stove and standard

\begin{tabular}{lccc}
\hline $\begin{array}{l}\text { Emission } \\
\text { parameters }\end{array}$ & $\begin{array}{l}\text { Biomass } \\
\text { gas stove }\end{array}$ & $\begin{array}{l}\text { Traditional } \\
\text { stove }\end{array}$ & $\begin{array}{l}\text { Thai exhaust } \\
\text { gas emission } \\
\text { Standard }\end{array}$ \\
\hline $\mathrm{O}_{2}(\%)$ & 12.59 & 17.12 & N/A \\
$\mathrm{CO}(\mathrm{ppm})$ & 385 & 1128 & 690 \\
$\mathrm{CO}_{2}(\mathrm{ppm})$ & 7.37 & 3.40 & N/A \\
$\mathrm{NO}_{\mathrm{x}}(\mathrm{ppm})$ & 99 & 99 & 200 \\
$\mathrm{SO}_{2}(\mathrm{ppm})$ & 0 & 0 & 60 \\
$\mathrm{H}_{2}(\mathrm{ppm})$ & 8 & 153 & N/A \\
\hline
\end{tabular}

\section{CONCLUSION}

This work confirmed that the efficiency of both stoves is so similar and the exhaust gas emission of the designed stove is less than the traditional stove. Therefore, this household biomass gas stove could replace the traditional clay brazier stove.

\section{REFERENCE}

[1] Suvarnakuta P and Suwannakuta P 2006 Biomass cooking stove for sustainable energy and environment Conf. SEE 2006 1-5

[2] Supramano D and Inayati F 2013 Performance of a biomass-gas stove fuel of rubber wood pellets Conf. QIR 393-398

[3] Odesola I F and Kazeem A O 2014 Design, construction and performance evaluation of a biomass stove JETEAS 5 $5358-362$

[4] Solapure V R, Motgi N S, Jangale Y N and Patil D Y 2017 Design and performance analysis of biomass cook stove IJERT 67 296-299

[5] Igboanugo A C and Ajieh M U 2017 Design and construction of biomass stove for cooking in rural settlements in nigeria RJEES 22 351-359

[6] The Ministry of Industry 2006 Notification of the Ministry of Industry: determination of the amount of contaminations in the air released from the factory 2006 Gazetted 123125 $7-11$ 